\title{
RESISTING MORBIDITY AND MORTALITY (RMM): AN EQUITABLE PUBLIC HEALTH
}

\section{R. Vinodh Rajkumar.}

Physiotherapist, Anthropologist \& Gerontologist. Director - Prabhanjeet Fitness Research Institute OPC Private Limited, Bangalore, Karnataka, India.

\section{ABSTRACT}

Every citizen deserves a lengthy, healthy and successful life. Survival competence and successful ageing basically require (i) ability to counteract gravitational force through adequate muscle strength, flexibility and postural control (ii) healthy nutrition (iii) optimal respiratory efficiency at rest and during physical activity (iv) mental health and ( $v$ ) supportive family. Lifespan of people is basically under the control of both individual and community participation. The burden for the individual after acquiring either communicable or non-communicable diseases is always unique, based on numerous variables like age, gender, socioeconomic status, occupation, lifestyle, severity of the disease, co-morbidities and access to legitimate health services. If the burden of the morbidity is not alleviated effectively, various crippling effects interweave and lead to irreversible loss of structures and functions, eventually deteriorating or destroying the competence to sustain an occupation or the level of independence. Mishaps, calamities and wars are also capable of exerting immediate effect to cause irreparable damages in the body (burns, spinal cord injuries, head injuries, fractures) forcing the sufferer to endure a troublesome life. Though harms to the body are unpredictable events, the extent at which every individual and the community as a whole are prepared with skills and technology to encounter them, controls the outcomes. Some disease states demand prolonged or lifelong health care that relies on affordability and family structure. On the other hand, completely costless health services are unrealistic and unsustainable to private sectors or private practitioners in the medical field, excluding sporadic exceptions where the health care is rendered on humanitarian basis. To certain extent, volunteers could provide different types of support using limited resources (few examples are walking aids, medicine supply, water supply, food supply, housing, blood donations, medical camps) to save or sustain life. But very often, many diseases require extensive interdisciplinary approach where multiple specialties are involved, so the total cost of the medical procedures (diagnosis and treatment) get elevated, due to which the deprived will be forced to limit or avoid or procrastinate treatments facilitating chances for the disease to mature incurably. The rehabilitation of patients is explicitly complicated but prevention of diseases looks less complicated if the public health model accentuates its focus on exercise, nutrition and health education to powerfully resist morbidities and premature mortalities through integrated efforts of health care professionals and all other overlapping domains. Based on substantial literature support, this article proposes a framework 'SHARE' to encourage necessary refinements to flourish the civilization as scrupulous as possible. It is also need of the hour for professionals of various disciplines to examine how their expertise could support this framework.

KEY WORDS: Public Health, Life Expectancy, Salutogenesis, Mortality, Morbidity, Exercise, Nutrition, Epidemiology, Spiritual Intelligence, Population ageing

Address for correspondence: R. Vinodh Rajkumar, Physiotherapist, Anthropologist \& Gerontologist. Director - Prabhanjeet Fitness Research Institute OPC Private Limited, Bangalore, Karnataka, India. E-Mail: dreamofkalam@rediffmail.com

Access this Article online

Quick Response code

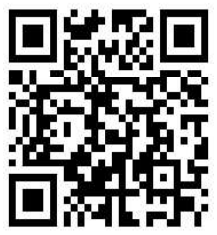

DOI: $10.16965 /$ ijpr.2020.177
Journal Information

International Journal of Physiotherapy and Research

ISSN (E) 2321-1822 | ISSN (P) 2321-8975

https://www.ijmhr.org/ijpr.html

DOI-Prefix: https://dx.doi.org/10.16965/ijpr

(cc) $\mathrm{Br}-\mathrm{NB}-\mathrm{BA}$
Received: 12 Oct 2020

Peer Review: 13 Oct 2020

Revised: None

Article Information

Accepted: 12 Nov 2020

Published (O): 11 Dec 2020

Published (P): 11 Dec 2020 


\section{INTRODUCTION}

Human body is generally respected from the stage of embryo till funeral but the lifespan of individuals remains enigmatic. In particular, the lifespan of the family members or beloved ones, is the mainstay for a cheerful life. Loss of family members at any stage is a catastrophe. During the course of life, ailments tend to conquer and devastate the health of the individuals. Ideally, no ailment is minor or benign, as it can expand its influence to collapse multiple functions of the body to the extent of causing irreparable complications if suitable interventions are not made in right time. There could be multiple reasons for inability to receive appropriate interventions like (i) Awareness among public (ii) Affordability of the individuals (iii) Accessibility to health care and (iv) Advancement in the profession. Additionally, the absence of a "School of Thought" in health care is conspicuous. School of Thought must ideally align with 'healthy ageing for all' which is possible only if we integrate self-discipline, community participation, inter-disciplinary researches and Government policies, to resist morbidities and mortalities on the basis of an equitable public health model. When we consider healthcare reform and new approaches to structuring health care systems, we must recognize that by avoiding long-term periods of morbidity, we reduce healthcare costs and improve the lives of patients at the same time, so "Compression of morbidity," of James Fries holds that if the age at the onset of the first chronic infirmity can be postponed more rapidly than the age of death, then the lifetime illness burden may be compressed into a shorter period of time nearer to the age of death [1].

Health disparities occur by race, ethnicity, sex, socioeconomic status, and sexual orientation, with inequities in screening, incidence, treatment, and mortality across a number of diseases and viewing health disparities through a lens that incorporates social/ environmental conditions as upstream factors (socioeconomic status and discrimination, that influence individual behavior, disease, and health status) in multilevel models better allows us to design and implement interventions targeted at levels downstream from those conditions [2]. Increased wealth and power come at the expense of exacerbating inequality affecting others due to the interconnectedness of today's globalised world and very often health professionals' training focuses on downstream individual intervention approaches like smoking cessation, diet improvement, at the expense of upstream determinants like food marketing, trade agreements [3].

Evolution faces enormous impediments which must be successfully managed through intellectual strength and teamwork of all the members in the society, under the aegis of an efficient political organization. "History has shown us the dramatic improvements in health outcomes and life expectancy that follow improvements in housing, sanitation, drinking water, education, employment, working conditions, food supply, transport infrastructure, and other social determinants of health. The fundamental determinant of sustainability - a healthy planet and environment. Public health must be at the forefront of action to deal with traditional environmental risks, and to mitigate and adapt to climate change; and good scientific policy must drive both analysis and actions" [4].

Demographic trends and epidemiological transitions must be under constant vigilance of Government through its multiple specialized departments to set priorities. "Population ageing is a pervasive and accelerating phenomenon. Three levels-(i) the national (increasing financial pressure like welfare schemes); (ii) the communal (urbanization, living conditions in rural areas, accessibility to services); and (iii) the individual levels (loneliness, social isolation)-are applied to structurally analyze the expected challenges related to population aging both in developed and developing countries. Among them, the communal level should be emphasized, as local and autonomous initiatives will be a critical measure in responding to diverse development challenges. The core challenge at the communal level is about securing 
adequate living conditions for all generations and maintaining the livelihood of societies while facing population aging challenges" [5].

A compassionate society is pivotal for lengthy, healthy, successful and meaningful lifespan of all the individuals. "For egalitarians, humans should be treated equally unless there is a justified reason for treating them unequally. The goal of egalitarianism is to achieve in theory and policy a specific framework of socio-political arrangement that will bring about the elimination of socioeconomic inequalities. Egalitarianism is significant because it provides the moral framework that links the personal and the political spheres in a manner that invigorates policies on healthcare, education, employment opportunities, and so on" [6]. Though the lifespan of the people is apparently better but the ageing-related health complications are highly individual-specific and could begin at an early age, constantly worsen and persist till death, so controlling the morbidities and mortalities is a daunting task. One of the primary reasons for this deviation from healthy ageing trajectory is our incomplete understanding of the human diversity on the basis of body constitution, lifestyle, fitness level, diseases and treatments that affect the humans at individual level [7].

"Two measures commonly used for epidemiological surveillance are morbidity and mortality to describe the progression and severity of a given health event. Morbidity is the state of being symptomatic or unhealthy for a disease or condition, usually represented or estimated using prevalence or incidence whilst Mortality, on the other hand, is related to the number of deaths caused by the health event under investigation, communicated as a rate or as an absolute number. Morbidity and mortality are two types of retrospective information that allows for continuous evaluation of the efficacy of either a specific health care system or an implemented intervention in place" [8]. Sharing the survival resources, instead competing for, could be envisaged as the best mechanism for flourishing the civilization scrupulously. Framework 'SHARE' aims at revisiting the present state of civilization, assessing its perilous errors and do necessary refinements by encompassing (i) Spiritual Intelligence (ii) Holistic Health (iii) Agriculture (iv) Research and (v) Eldercare.

Spiritual Intelligence: Effective functions of the humans can be expected if their body and mind work in unification, though on many occasions it may not be possible. It might need determined learning and practicing channelizing the unique human potential for productivity and benevolence. Living with no pressure, concern, fear, and anxiety, as well as increase of spiritual growth makes individuals stronger and brings about opportunities to take part in innovative activities and do their jobs more clearly meaningfully and purposefully, therefore education of skills related to spiritual intelligence in all levels and for all individuals notably affects fulfillment of transcendentalism and meaningfulness of the society [9].

There is no empirical evidence that can actually and unambiguously establish a coherent model that explains the participation of Spiritual Intelligence (SI) in the process of looking for the meaning of life, but SI cannot be omitted as a link in the chain of psychic phenomena and events that lead to discovering the meaning of life [10]. Spiritual capital becomes increasingly important role especially in the effort to build intelligent man with high intellectual and human who is good at managing emotion and social relation, which will deliver human to meaningfulness of life [11]. Spiritual Intelligence helps to fulfill the potentialities of the individuals' abilities through the non-cognitive virtues to prepare them to solve the everyday problems for life creatively and constructively in the new situation of the socio-psycho-physical environment for attaining the highest knowledge and wisdom [12]. Spiritual intelligence is the expression of innate spiritual qualities through your thoughts, actions and attitude and it helps a person to (i) understand and simplify the personal life, family life and working life (ii) calm and focused in the face of crisis and chaos, a more selfless and humane attitude towards others and a more enlightened and relaxed perspective on life (iii) be more successful 
thereby contributing in the growth and development of an organization [13].

"Spiritual intelligence is a higher dimension of intelligence that activates the qualities and capabilities of the authentic self (or the soul), in the form of wisdom, compassion, integrity, joy, love, creativity, and peace. The Spiritual Intelligence Self-Report Inventory (SISRI-24) developed by King (2008). It consists of 24 items. It consists of 4 subscales namely: Critical Existential Thinking (CET), Personal Meaning Production (PMP), Transcendental Awareness (TA) and Conscious State Expansion (CSE)" [14]. These literatures kindle the curiosity to evaluate the present state of spiritual intelligence among the citizens and the figure out the ways to improve it to contribute to the nation-building.

Holistic Health: Physiologic competence to survive without morbidities must be considered as the top-most priority by the humans. Settled way of living, after the advent of agriculture, has obviously diminished the human fitness for ideal health. Modern civilization has diverse occupations but they are either not unified for a common goal or not aware that they must be unified for a common goal, eventually lacking mutual respect for each other's indispensable contribution to welfare of the society. Both perseverance for recognition and deprivation of recognition could confine many individuals in deep stressful situations, in which the focus on personal health becomes problematic for several individuals. Individual-specific stressful state and corresponding coping strategies, could manufacture indefinite variants of every disease which can be only managed through holistic care approach. Health is a relative state in which one is able to function well physically, mentally, socially, and spiritually to express the full range of one's unique potentialities within the environment in which one lives and the lay perspective on health appears to be characterized by three qualities: (i) wholeness - absence of disease is not enough - the life situation as a whole must be taken into consideration (ii) pragmatism being realistic in life-expectations and (iii) individualism - strategies for improving health must be individualized [15].

The impact of communicable and non-communicable diseases on human body will also be highly individual-specific, chiefly on the basis of their somatotype and various other adaptations to the environment. "Humans evolved in a hostile microbial environment, and natural selection by infectious disease may be one of the major causes of human genetic diversity, particularly in the immune system. Genetic epidemiology provides a potentially powerful way of identifying the critical molecular events required for an infectious agent to invade a human host, and for the host to eradicate or succumb to the infection. A deeper understanding of the genetic factors that determine susceptibility to infection may ultimately provide clues to the prevention of a much wider range of common diseases" [16].

Nutritional status, breathing efficiency and the detoxification efficiency of the body determine the individual-specific $\mathrm{pH}$ level which is the most fundamental biochemical determinant of homeostasis. Human beings vary significantly in their biochemical make-up, hence, in the holistic view, disease processes should be understood in a broader context than linear causation; that is, as resulting from interaction of multiple factors [17]. Humans have been capable of maximizing their intelligence through sustained excavation of their expertise to overcome the problems in different facets of life in order to live in good health and such expertise should not be confined to one particular area but can be transmitted to various other parts of the globe. "It is no longer possible for this generation in the Western world to ignore or denigrate the medicine and healing practices used by hundreds of millions in other cultures and what is obviously needed is a retreat from the innate sceptical reaction of much of the stance of western medicine, the development of a mutual respect for other cultures and their achievements, and a genuinely open, scientific and wholistic approach to the issues, especially in this context, to other practices of whole person healing" [18].

COVID-19 interconnected the nations because this pandemic became a common enigmatic problem but even this massive, unified effort 
could not obtain precise solutions yet. "If exposure to a necessary agent is homogeneous within a population, then case/control and cohort methods will fail to detect it: they will only identify markers of susceptibility. The corresponding strategies in control are the 'high-risk' approach, which seeks to protect susceptible individuals, and the population approach, which seeks to control the causes of incidence. The two approaches are not usually in competition, but the prior concern should always be to discover and control the causes of incidence" [19]. While diagnosing and curing the diseases are quite complicated, the socioeconomic variations, adequate highly skilled manpower in the health sector and corresponding schemes and policies of the Government determine the quality and efficiency of health care to the people. "Widening the gap between the rich and the poor has damaging health and social consequences. While financial inclusion and social security measures are being implemented by the Government to bridge economic inequalities, health sector too must ensure that health disparities between and among social and economic classes are also addressed adequately. The unprecedented demographic changes underway are likely to contribute to a substantially increased labour force. However, it will benefit the country only if the population is healthy. India at present suffers from the triple burden of disease the unfinished agenda of infectious diseases; the challenge of noncommunicable diseases (NCDs), linked with lifestyle changes; and emergence of new pathogens causing epidemics and pandemics. In addition, the health infrastructure is already over-stretched and needs to be strengthened to enable it confront these challenges in the twenty-first century" [20].

Disasters are associated with predictable and unpredictable short-term and long-term repercussions. "Due to lockdown, the migrant workers are more prone to social, psychological, and emotional trauma in such situations, emanating from fear of neglect by the local community and concerns about their families' wellbeing and safety in their native places. COVID-19 pandemic is causing severe anxiety and depressive symptoms in migrants' workers. Therefore, it is equally important to focus on the mental health issues of this vulnerable population. These people's mental health needs must be made an urgent public health priority because social isolation or living in a shelter house can have a significant impact on their mental health" [21].

In general, humans focus on socialization, self-actualization, and pursuits, and avoid thinking about death, though they are aware that the ageing process will eventually lead to loss of life. Death is end-of-life (EOL) process and dying is the end process of the life [22]. The irreversible loss of physiologic functions coupled with loss of social status deter the ageing individuals from finding a productive way of living thereafter. No intervention will slow, stop, or reverse the aging process in humans and if age changes are the greatest risk factor for age-associated diseases (an almost universal belief), then why is the study of aging virtually neglected? [23]. If our goal is to develop interventions to slow the increase in biological aging as a function of chronological time, and thus facilitate health promotion and disease prevention, we need to first come up with clinically valid measures of the underlying biological process and/or classification criteria for what it means to be biologically, rather than chronologically, "aged." [24]. Thus far, the most promising, new biological age predictor is the epigenetic clock; however, its true value as a biomarker of aging requires longitudinal confirmation [25].

Crippling effects of ageing and age-related diseases will lead to frailty and extreme level of dependence for survival. There is a need to integrate palliative care into health-care training and the national medical, nursing and allied health council should structure and implement palliative care education into basic health-care training [26]. Dealing with holistic health and lengthy lifespan for all requires much higher level of interdisciplinary collaboration to construct an advanced public health model. Antonovsky distinctly stated the salutogenesis was not limited by the disciplinary borders of one profession but rather an interdisciplinary approach and a 
question of bringing coherence between disciplines and realise what connects them through the people's ability to comprehend the whole situation and the capacity to use the resources available (called as sense of coherence - SOC) to move in a health promoting direction [27].

Demands of life, Potentials (biologically-given and personally acquired), Social determinants of health and Environmental determinants of health are the components of the Meikirch model of health and for a complete appraisal of a patient's condition all these components and their interactions must be considered and investigated [28].

Agriculture: Agriculture played the dominant role in enabling the transition from huntergatherer lifestyle to urbanisation and globalisation. Agriculture has been a crucible of evolutionary change ever since its inception thousands of years ago, and this change permeates agricultural endeavours at all levels of biological organisation, ranging from the individual gene through to whole communities [29]. Enhanced understanding about the environment and acquired scientific ability of the humans to preserve and multiply the precious food resources have been ensuring the nutritional requirements of nearly eight billion people in the globe at present. Environmental constraints limit trees' reproductive activity in their natural, wild habitats, resulting in poor, irregular productivity yet early fructification and regular, high rates of productivity have been selected by people, unconsciously and consciously [30]. Interdisciplinary and transdisciplinary health care approaches and researches in the medical field must be expedited and strengthened keeping "Foods Obstruct and Overcome DiseasesFOOD" as the foundation [31]. Agriculture is a laborious and disease-prone occupation. Unquestionably, farmers' health deserves primary focus. In India, it is estimated that $<" 16,000$ farmers die by suicide each year, and at rates far above those of the general population [32].

Farming is associated with a range of physical and mental health risks because of the hard work under challenging conditions [33].
Farmers are extensively using pesticides for pest control in agriculture and there is a need for continuous pesticide safety education along with training to the farmers regarding use of personal protective devices, personal hygiene and sanitation practices during and after application of pesticides [34].

The four most-cited influences on farmers' mental health in the reviewed literature respectively were pesticide exposure, financial difficulties, climate variabilities/drought, and poor physical health/past injuries [35]. India's $54.6 \%$ of the population is engaged in agriculture and allied activities and prevalence of musculoskeletal disorders (MSDs) is common among farmers as agriculture work is highly physically demanding and it had affected farmers adversely in terms of long disability days resulting into economic loss in terms of failure to work to earn and expenditure on treatment [36].

Forward bending, twisting, exposure to vibrations while driving tractors coupled with heavy load carrying in arduous farming predisposes the farmers to continued physical stresses and work-related musculoskeletal disorders (WMSDs) in which Low back pain is the most common type of MSD followed by Knee, Shoulder, Neck, Upper back, Elbow, Hip, Wrist and hand, and Ankle and Foot, and they could become chronic because of negligence or unavailability of proper health care facilities as well as lack of ergonomic education among farmers [37]. Poor postures and lack of ergonomic awareness in the farming community are the two principal causative factors contributing to the development of MSDs [38]. Due to low rate of health care utilization for the problems associated with MSDs, interference with the occupational activities and also daily routine activities of the workers takes place, which warrant immediate medical attention and rehabilitation measures for change in occupational work of the affected individuals [39]. "Sustainable development is the management and conservation of the natural resource base and the orientation of technological and institutional change in such a manner as to ensure the attainment and continued satisfaction of human needs for the 
present and future generations. Such sustainable development (in the agriculture, forestry and fisheries sector) conserves land, water, plant and animal genetic resources, is environmentally non-degrading, technically appropriate, economically viable and socially acceptable. Therefore, to achieve sustainable agriculture development the optimum use of natural resources, human resources, capital resources and technical resources are required" [40].

Knowledge about nutrition and food availability propels the evolution to become more physically and mentally efficient humans. "The main drive of improving manual actions and tool making could be to obtain more food. Our ancestor got more meat due to more successful hunting, resulting in more caloric intake, more protein and essential fatty acid in the meal. The nervous system uses disproportionally high level of energy, so better quality of food was a basic condition for the evolution of huge human brain. The size of human brain was tripled during 3.5 million years, it increased from the average of $450 \mathrm{~cm} 3$ of Australopithecinae to the average of $1350 \mathrm{~cm} 3$ of Homo sapiens" [41].

Research: Research are needed to solve problems and set base for sustainability. Precision of any occupation/profession can only be attained after countless number of trials and errors. During curious engagement in experimentations, humans have learned to standardize the research because the findings must be reliable, safe, and productive. The need for the research must be justified by stating the research gap(s), problem, or question(s), and an explanation of how the proposed research will contribute to existing body of knowledge (novelty) as well as explaining how the outcomes of the research are likely to benefit the following stakeholders where applicable: (a) academia, (b) individuals and communities, (c) industry and commerce, and (d) policymakers nationally and internationally [42].

The research must be disseminated (published in a journal or presented at a professional meeting), with a detailed description of the methods used because unless the research is reported, others cannot utilize or examine it to determine whether they would come to the same conclusion [43]. Creativity and critical thinking are of particular importance in scientific research [44]. Any social action plan, scheme, or program for welfare or intervention can be formulated only on the basis of data generated by research findings and the generation of large and varied pieces of data across disciplines is a strength, while the absence of methodological rigor, integration of research effort, and the building of theory are the lacunae [45]. Importantly, there are widespread individual differences in the crucial facets of human intelligence (ability to reason, solve problems, and learn) which lead to human differences in the general ability to cope with challenging situations [46]. It is obviously advantageous to harness the unique perspectives and competencies of the individuals to solve the problems of human life and contribute to progress of the civilization.

Eldercare: Emphasis on the needs of older adults is usually neglected though it is widely known that their level of independence declines and their life becomes miserable especially after acquiring co-morbidities. "In India, the elderly suffers from dual burden of communicable and non-communicable diseases besides impairment of special sensory functions like vision and hearing and other degenerative diseases. Poor geographical access and high cost of treatment also lead to poor utilization of health care especially among the elderly. The elderly is also prone to abuse in their families or in institutional settings. Geriatric care is conspicuously missing from the medical education curriculum. Similarly, the nursing and other paramedical staff members are not formally trained in providing care for elderly patients. There is no specialized training in geriatrics in most medical schools in India" [47]. "Old age is heterogeneous, but a large proportion of older persons is affected by multiple chronic diseases, resulting in a wide range of needs. 
Health systems will have to adapt to this new situation while still providing appropriate responses to acute diseases affecting all ages. Although future needs are difficult to quantify, their nature is already apparent. Providing for these needs will require a major investment in manpower, a diversification of services delivered by health care systems, changes in the training of health professionals and extensive research to define effective treatments for elderly patients with multiple co-morbidities" [48]. "Because the rate of ageing varies immensely among individuals, humans become increasingly different from each other with age. Thus, chronological age fails to provide an accurate indicator of the ageing process. The goal of human ageing research is not necessarily to extend lifespan, but instead to extend the healthy years of life" [49].

"Senescence is an irreversible form of long-term cell-cycle arrest, caused by excessive intracellular or extracellular stress or damage. The purpose of this cell-cycles arrest is to limit the proliferation of damaged cells, to eliminate accumulated harmful factors and to disable potential malignant cell transformation. As the biological age does not have to be in accordance with the chronological age, it is important to find specific hallmarks and biomarkers that could objectively determine the rate of age of a person. elderly age was classified into three periods: Elderly or early old age, senile or middle old age and late old age" [50].

"Methylation levels of multiple CPG sites display a strong correlation to age common between individuals of the same species. Collectively, methylation of such CPG sites could be used as "epigenetic clocks" to predict biological age. Furthermore, the discrepancy between epigenetic and chronological ages could be predictive of all-cause mortality and multiple age-associated diseases. Random changes in DNA methylation (epigenetic drift) could also affect the aging phenotype, causing accidental changes in gene expression and increasing the transcriptional noise between cells of the same tissue. Both effects could become detrimental to tissue functioning and cause a gradual decline in organ function during aging. Strong evidence shows that epigenetic systems contribute to lifespan control in various organisms. Similar to other cell systems, the epigenome is prone to gradual degradation due to the genome damage, stressful agents and other aging factors. However, unlike mutations and many other hallmarks of aging, age-related epigenetic changes could be fully or partially reversed to a "young" state" [51].

"Geriatric syndromes represent clinical conditions common in older adults that share underlying causative factors and involve multiple organ systems (incontinence, cognitive impairment, delirium, falls, pressure ulcers, pain, weight loss, anorexia, functional decline, depression, and multi-morbidity) and the Physicians should consider the possibility of patient abuse by caregiver if circumstances and physical findings suggest it, he/she should consider referral of the patient to a social worker, patient resource manager, or geriatric assessment team with the goal of helping the patient and the caregiver" [52]. Mobility impairment contributes to the construct of frailty (a state of heightened vulnerability) and channels adverse events like complex system failure, with higher-order disturbance, such as mobility and balance disturbance, as a consequence, therefore clinical measurement of mobility and balance should be prioritized [53].

Quality of hospital including its staff can be enhanced by developing geriatric-specific competencies which can help them to understand and treat complex health problems specific for the older population [54]. "Ageism is a form of prejudice or prejudgment that shapes perceptions. Ageist terms tend to diminish older adults, yet ageism is rampant in health care, stereotyping older folks as sick, frail, and physically dependent. The terms senile, demented, and aged are unfortunate terms once in common use among physical therapy personnel. While these terms have mostly disappeared, there is still a term in common use that needs to disappear, the term elderly. The term older adult or older person is respectful and should be the 
standard term in this journal" [55].

"In an anticipation of the rising geriatric population in India, the Central government constituted the National Policy for Older Persons in 1999 to promote the health and welfare of senior citizens in India. A major strategy of this policy is to encourage families to take care of their older family members. The policy also encourages voluntary organizations to supplement the care provided by the family and provide care and protection to vulnerable elderly people. The implementation of this policy, particularly in the rural areas, has been negligible and calls for a scaling-up of programs to address the physical, psychological, and social needs of the poor. Due to breakdown of the joint family system and the migration of the younger generation to the towns and cities, the elderly parents in the villages are left to fend for themselves. Too old to work and with little or no source of income, the elders are struggling even to satisfy their basic needs. More than a decade since its inception, it is now the right time to assess the implementation of our geriatric health policy and scale-up programs so that the elderly in our country, irrespective of urban and rural, will have a dignified and good quality life" [56].

"The traditional ancient culture with joint families and common land holding never posed a problem for elderly care but in the last few decades due to modernization the elderly today does not enjoy the same status as they enjoyed in past. This fast pace of social change is affecting traditional care giving mechanisms for the elderly. Government of India has made efforts to tackle the problem of elders' economic insecurity by launching schemes such as the National Policy on Older Persons, the National Old Age Pension Programme and the Annapurna Programme. It must be remembered that comprehensive care to the elderly is possible only with the involvement and collaboration of family, community and the Government" [57]. "The dwindling of the joint family, the rise of dual-career families, a possible shift in filial piety values, the increasing life expectancy with greater chances of a prolonged old age characterized by poverty, degeneration, more empty-nest years, and dependency, have all added to the seriousness of the problem and made the elderly more susceptible than ever to abusive treatment. A greater role is envisaged for Non-Governmental Organizations (NGOs) than the state in the care of the elderly, particularly in providing support services to family caregivers" [58].

\section{DISCUSSION}

It will be highly incomplete if any problem or disease of humans are managed by only one subject matter expert or domain. Many domains overlap in their functions, therefore collective ideas and actions of different subject matter experts would help in rendering rapid and sustainable results. Moreover, each domain also has been expanding its scopes through continuous scientific pursuits eventually contributing novel insights but such contributions will go futile if all the domains fail to understand their overlapping or interdependent functions to deal with countless number of variables to provide 'holistic health' and 'healthy lifespan' for all. Survival competence and successful ageing basically require (i) ability to counteract gravitational force through adequate muscle strength, flexibility and postural control (ii) healthy nutrition (iii) optimal respiratory efficiency at rest and during physical activity (iv) mental health and (v) supportive family. Insufficient exposure to gravitational forces leads to Gravitational Torque Deficiency Syndrome [59].

Breathing cycles must be smooth tides on which the major proportion of life should sail without facing any turbulence and well-balanced breathing pattern is a lifestabilizing and life-propelling force "Pulmonary Panacea"[60]. Many erroneous body movements organize themselves as the earliest asymptomatic biomechanical dysfunctions of unhealthy ageing [61]. Assessment of somatotype employing Heath-Carter method is essential in fitness evaluations and clinical decision-making [62]. Single leg balance (SLB) is a key neuro-biomechanical asset of several fundamental and advanced closed kinetic chain activities of lower limb, hence, from the 
perspectives of healthy ageing and fall prevention strategies, there is a compelling need to explore and devise a safe and effective SLB assessment tool to incorporate in multifactorial health evaluations and gerontological education [63].

Non-athlete population were able to exhibit their maximum running speeds and step lengths on the ground in outdoor settings [64]. Human mind and body must remain integrated to be serene, disease-free and, competent enough to overcome various stressors independently [60]. Fear and anxiety are potent enough to disturb the homeostasis of the body particularly by causing imbalance in the functions of autonomic nervous system, leading to aggravation of fight or flight response [7]. Acute stress-induced activation of SAMS (Sympathoadrenomedullary system) can be a health hazard [65]. Genetics, Epigenetics, Nutrition, Exercise and Somatotype (G.E.N.E.S) can be amalgamated to enhance the precision of all the treatments without any trade-offs" [31]. Sarcopenia represents a loss of muscle strength and mass in older individuals and is a major determinant of fall risk and impaired ability to perform activities of daily living, often leading to disability, loss of independence and death [66].

Combination of strength training and flexibility exercises are important to preserve various fundamental biomechanical functions of the body and control the trajectory of healthy ageing. Optimally flexible muscles support ideal postures, basic movements of Activities of Daily Living and advanced skills of Exercise, Sports and Occupation. We can envisage far superior health care systems and policies if the Government dexterously gathers fundamental health-related data of every citizen once in a year (Height, Weight, Somatotype, Blood pressure, Heart rate, Respiratory rate, Blood glucose, Blood cholesterol, Existing morbidities, Medicines being consumed) to understand the disease trends in the country and keep the health departments in competent state to manage any health crises [7]. None of the diseases should be given trivial attention because many functions of the body happen involuntarily. The autonomic nervous system permeates all organ systems with its pathways and there is absolutely no disease or ailment that does not involve autonomic regulation or innervation disorders [67]. Through voluntary efforts (like exercise, balanced food intake, avoiding substance abuse, opting rewarding social environment, improving cognitive abilities, seeking spiritual intelligence) the optimal functions of autonomic nervous system could be preserved. Holistic health care must include various aspects, aforementioned to empower humans to live courageously and develop strong rapport with nature.

\section{CONCLUSION}

Inequitable public health and security, occupational hazards of agriculture, abandonment of older adults and insufficiently utilized individual-specific human potential are the major disorders that deserve thoughtful attention in political administration. A competitive society does not much care about others' sufferings and socioeconomic inequalities, but a compassionate society would chiefly emphasize on caring and sharing to ultimately manoeuvre the civilization to excellence. This extensive literature review gives a new direction to blend spiritual intelligence, Antonovsky's salutogenesis, Fries' compression of morbidity and Meikirch's model of health to prevent early onset of age-related morbidities and premature mortalities. The philosophy of interdisciplinary health care approaches and researches should be accentuated by the Government and it would also be ideal if all the occupations endeavour to either directly or indirectly support agriculture and farmers because food is the sole determinant of subsistence and evolution. It is also need of the hour for professionals of various disciplines to examine how their expertise could connect with Resisting Morbidity and Mortality (RMM) to provide the best possible holistic health care and productive lifespan for all. RMM should be the prime goal of equitable public health by applying the framework 'SHARE'.

\section{Conflicts of interest: None}




\section{REFERENCES}

[1]. Swartz A. James Fries: healthy aging pioneer. Am J Public Health. 2008;98(7):1163-1166.

https://doi.org/10.2105/AJPH.2008.135731

PMid:18511711 PMCid:PMC2424092

[2]. Gehlert S, Sohmer D, Sacks T, Mininger C, Mc Clintock M, Olopade O. Targeting health disparities: a model linking upstream determinants to downstream interventions. Health Aff (Millwood). 2008;27(2):339349.

https://doi.org/10.1377/hlthaff.27.2.339

PMid:18332488 PMCid:PMC2494954

[3]. Oni, Tolu; Yudkin, John S; Fonn, Sharon; Adongo, Philip; Kaseje, Margaret; Ajuwon, Ademola; Doyal, Lesley; London, Leslie. Global public health starts at home: upstream approaches to global health training. The Lancet Global Health, ISSN: 2214-109X, 2019; 7 (3): e301-e302.

https://doi.org/10.1016/S2214-109X(18)30558-8

[4]. Weeramanthri TS, Bailie RS. Grand challenges in public health policy. Front Public Health. 2015;3:29. Published 2015.

https://doi.org/10.3389/fpubh.2015.00029

[5]. Shogo Kudo, Emmanuel Mutisya, Masafumi Nagao. Population Aging: An Emerging Research Agenda for Sustainable Development. Soc. Sci. 2015, 4(4), 940966; https://doi.org/10.3390/socsci4040940

[6]. Afolayan A. Egalitarianism. In: ten Have H. (eds) Encyclopedia of Global Bioethics. Springer,Cham. 2015.

https://doi.org/10.1007/978-3-319-05544-2_166-1

[7]. R.Vinodh Rajkumar. Epidemiological Intersection: The Revelation of Covid - 19 Pandemic. Int J Physiother Res 2020;8(2):3438-42.

https://doi.org/10.16965/ijpr.2020.126

[8]. Hernandez JBR, Kim PY. Epidemiology Morbidity And Mortality. [Updated 2020 Feb 2]. In: StatPearls [Internet]. Treasure Island (FL): StatPearls Publishing; 2020 Jan-. Available from: https://www.ncbi.nlm.nih.gov/books/NBK547668/

[9]. Sahebalzamani M, Farahani H, Abasi R, Talebi M. The relationship between spiritual intelligence with psychological well-being and purpose in life of nurses. Iran J Nurs Midwifery Res. 2013;18(1):3841. https://doi.org/10.4103/2345-5756.231405

[10]. Skrzypiñska, K. Does Spiritual Intelligence (SI) Exist? A Theoretical Investigation of a Tool Useful for Finding the Meaning of Life. J Relig Health. 2020. https://doi.org/10.1007/s10943-020-01005-8 PMid:32108312

[11]. Dian Novita Siswanti et al. J. Phys.: Conf. Ser. 1028 012193. 2018.

https://doi.org/10.1088/1742-6596/1028/1/012193

[12]. Prem Shankar Srivastava. Spiritual Intelligence: An Overview. International Journal of Multidisciplinary Research and Development. 2016;3(3):224-227.

[13]. Dr.Jyoti Deepak Joshi, "Spiritual Intelligence" A Way of Life. International Journal of Scientific Research. 2016; 5(6):339-341.
[14]. R.Saranya, and Mrs. T. Sangeetha. "A study of spiritual intelligence in relation to achievement in science among secondary school students in Coimbatore educational district." International Journal of Research - Granthaalayah, 2017; 5(6):10-17.

[15].Svalastog AL, Donev D, Jahren Kristoffersen N, Gajoviæ S. Concepts and definitions of health and health-related values in the knowledge landscapes of the digital society. Croat Med J. 2017;58(6):431435. https://doi.org/10.3325/cmj.2017.58.431 PMid:29308835 PMCid:PMC5778676

[16]. Kwiatkowski D. Science, medicine, and the future: susceptibility to infection. BMJ. 2000; 321(7268): 10611065. doi:10.1136/bmj.321.7268.1061. https://doi.org/10.1136/bmj.321.7268.1061 PMid:11053181 PMCid:PMC1118849

[17]. Marc Lappé. Holistic health: a valuable approach to medical care. West J Med. 1979; 131(6): 475-478.

[18]. Roy R. Science and Whole Person Medicine: Enormous Potential in a New Relationship. Bulletin of Science, Technology \& Society. 2002;22(5):374-390. https://doi.org/10.1177/027046702236890

[19]. Rose G. Sick individuals and sick populations. Int J Epidemiol. 2001;30(3):427-434. https://doi.org/ 10.1093/ije/30.3.427 PMid:11416056

[20]. Narain JP. Public Health Challenges in India: Seizing the Opportunities. Indian J Community Med. 2016;41(2):85-88. https://doi.org/10.4103/0970-0218.177507 PMid:27051080 PMCid:PMC4799645

[21]. Kumar K, Mehra A, Sahoo S, Nehra R, Grover S. The psychological impact of COVID-19 pandemic and lockdown on the migrant workers: A cross-sectional survey [published online ahead of print, 2020 Jun 20]. Asian J Psychiatr. 2020;53:102252. https://doi.org/10.1016/j.ajp.2020.102252 PMid:32593970 PMCid:PMC7305726

[22]. Zisook S, Shear K, Irwin S. Death, dying and bereavement. In: Sadock BJ, editor. Comprehensive Textbook of Psychiatry. 9th ed. Philadelphia: Lippincott Williams and Wilkins; 2009. pp. 2407-22.

[23]. Leonard Hayflick, Aging: The Reality: "Anti-Aging" Is an Oxymoron, The Journals of Gerontology: Series A. 2004;59(6):B573-B578.

https://doi.org/10.1093/gerona/59.6.B573 PMid:15215267

[24]. Morgan E Levine, PhD, Assessment of Epigenetic Clocks as Biomarkers of Aging in Basic and Population Research, The Journals of Gerontology: Series A, 2020; 75(3), 463-465. https://doi.org/10.1093/gerona/ glaa021 PMid:31995162

[25].Jylhävä J, Pedersen NL, Hägg S. Biological Age Predictors. EBioMedicine. 2017;21:29-36. https://doi.org/10.1016/j.ebiom.2017.03.046 PMid:28396265 PMCid:PMC5514388

[26]. Sharma H, Jagdish V, Anusha P, Bharti S. End-of-life care: Indian perspective. Indian J Psychiatry. 2013;55(Suppl 2):S293-S298. https://doi.org/10.4103/0019-5545.105554 PMid:23858271 PMCid:PMC3705699 
[27]. Lindström B, Eriksson M. Salutogenesis. Journal of Epidemiology \& Community Health 2005;59:440442.

https://doi.org/10.1136/jech.2005.034777

[28]. Bircher, Johannes \& Hahn, Eckhart. The Meikirch Model as a Conceptual Framework for Person Centered Healthcare. European Journal for Person Centered Healthcare. 2017;5:197-201.

https://doi.org/10.5750/ejpch.v5i2.1284

[29]. Thrall PH, Bever JD, Burdon JJ. Evolutionary change in agriculture: the past, present and future. Evol Appl. 2010;3(5-6):405-408.

https://doi.org/10.1111/j.1752-4571.2010.00155.x PMid:25567934 PMCid:PMC3352499

[30]. Goldschmidt EE. The Evolution of Fruit Tree Productivity: A Review. Econ Bot. 2013;67(1):51-62.

https://doi.org/10.1007/s12231-012-9219-y

PMid:23538880 PMCid:PMC3606516

[31]. R.Vinodh Rajkumar. Foods Obstruct and Overcome Diseases (FOOD): The Missing Interdisciplinary and Transdisciplinary Public Health Art till Covid-19 Pandemic. Int J Physiother Res 2020;8(5):3586-3594. https://doi.org/10.16965/ijpr.2020.155

[32].DominicMerriott. Factors associated with the farmer suicide crisis in India. Journal of Epidemiology and Global Health. 2016; 6 (4), 217-227. https://doi.org/10.1016/j.jegh.2016.03.003 PMid:27080191 PMCid:PMC7320464

[33]. Fraser CE, Smith KB, Judd F, Humphreys JS, Fragar LJ, Henderson A. Farming and mental health problems and mental illness. Int J Soc Psychiatry. 2005 Dec; 51(4):340-9.

https://doi.org/10.1177/0020764005060844 PMid:16400909

[34]. Satya Sai MV, Revati G D, Ramya R, Swaroop AM, Maheswari E, Kumar MM. Knowledge and perception of farmers regarding pesticide usage in a rural farming village, Southern India. Indian J Occup Environ Med 2019;23:32-6

https://doi.org/10.4103/ijoem.IJOEM_121_18 PMid:31040587 PMCid:PMC6477948

[35]. Sahar Daghagh Yazd, Sarah Ann Wheeler, Alec Zuo. Key Risk Factors Affecting Farmers' Mental Health: A Systematic Review. Int J Environ Res Public Health. 2019 Dec;16(23): 4849.

https://doi.org/10.3390/ijerph16234849

PMid:31810320 PMCid:PMC6926562

[36].Patil, Saket Anil \& Kadam, Yugantara \& Mane, AnupriyaSuresh \& Gore, AlkaDilip \& Dhumale, GirishBhimrao. The prevalence and health impact of musculoskeletal disorders among farmers. Medical Journal of Dr. D.Y. Patil Vidyapeeth. 2018; 11 (6): 485.

[37]. Gadhavi B, Shukla Y. Prevalence of work-related musculoskeletal disorders in farmers of Gujarat. International Journal of Research and Review. 2019; 6(11):231-236.

[38]. Garima Gupta, Tarique., Prevalence of musculoskeletal disorders in farmers of Kanpur-rural, India. Orthop Muscular Syst 2015;4:4.

[39]. Hemalatha K, Bharanidharan G, Anusha T. Prevalence of musculoskeletal disorder among agricultural workers in rural area of Tamil Nadu: A cross sectional study. HECS Int J Com Health and Med Res 2017;3(3):26-31.

[40]. Bethu Sudhakar. "Sustainable Agriculture Development in India: Issues and Challenges", Indian Journal of Research, 2016; 5(7), ISSN - 2250-1991, pp. 293-295.

[41]. Lakatos L, Janka Z. Az emberi agy és intelligencia evolúciója [Evolution of human brain and intelligence]. Ideggyogy Sz. 2008;61(7-8):220-229.

[42]. Abdulai RT, Owusu-Ansah A. Essential Ingredients of a Good Research Proposal for Undergraduate and Postgraduate Students in the Social Sciences. SAGE Open. 2014. https://doi.org/10.1177/2158244014548178

[43]. George A. Morgan, Jeffrey A. Gliner, Robert J. Harmon. Definition, Purposes, and Dimensions of Research. J. Am. Acad . Child Adoles C. Psychiatry, 1999; 8:2:P217219.

https://doi.org/10.1097/00004583-199902000-00023 PMid:9951223

[44].Pitchai Balakumar, Mohammed Naseeruddin Inamdar, and Gowraganahalli Jagadeesh. The critical steps for successful research: The research proposal and scientific writing: (A report on the preconference workshop held in conjunction with the 64th annual conference of the Indian Pharmaceutical Congress-2012). J Pharmacol Pharmacother. 2013 Apr-Jun; 4(2): 130-138.

https://doi.org/10.4103/0976-500X.110895 PMid:23761709 PMCid:PMC3669572

[45]. P.V.Ramamurti PhD, Perspectives of Research on Aging in India, Journal of Aging and Social Policy. 2003; 15:2-3, 31-43. https://doi.org/10.1300/J031v15n02_03 PMid:14696688

[46]. Roberto Colom, Sherif Karama, Rex E. Jung, Richard J. Haier, Human intelligence and brain networks. Dialogues Clin Neurosci. 2010; 12(4): 489-501. https://doi.org/10.31887/DCNS.2010.12.4/rcolom PMid:21319494 PMCid:PMC3181994

[47]. Jaya Prasad Tripathy, Geriatric care in India: A long way to go. J Midlife Health. 2014; 5(4): 205-206.

https://doi.org/10.4103/0976-7800.145176 PMid:25540574 PMCid:PMC4264287

[48]. Santos-Eggimann B. Evolution of the needs of older persons. Aging Clin Exp Res. 2002;14(4):287-292. doi:10.1007/BF03324452. https://doi.org/10.1007/ BF03324452 PMid:12462374

[49]. Heather E. Wheeler and Stuart K. Kim. Genetics and genomics of human ageing. Philos Trans R Soc Lond B Biol Sci. 2011; 366(1561): 43-50.

https://doi.org/10.1098/rstb.2010.0259

PMid:21115529 PMCid:PMC3001305

[50]. Slavica Dodig, Ivana Èepelak, and Ivan Paviæ. Hallmarks of senescence and aging. Biochem Med (Zagreb). 2019; 29(3): 030501.

https://doi.org/10.11613/BM.2019.030501

PMid:31379458 PMCid:PMC6610675

[51]. Ashapkin VV, Kutueva LI, Vanyushin BF. Epigenetic Clock: Just a Convenient Marker or an Active Driver of Aging?. Adv Exp Med Biol. 2019;1178:175-206. https://doi.org/10.1007/978-3-030-25650-0_10 
[52]. Susan P Bell , Nileshkumar Patel , Nish Patel, Rajesh Sonani , Apurva Badheka, Daniel E Forman. Journal of Geriatric Cardiology. 2016;13:1-7.

[53]. Eeles E, Low Choy N. Frailty and Mobility. Interdiscip Top Gerontol Geriatr. 2015;41:107-120.

https://doi.org/10.1159/000381200

PMid:26301984

[54].Sachin Ganorkar, Zarina Nahar Kabir, Nasreen Rustomfram, Harshad Thakur. Experiences of Older Persons in Seeking Care at a Private Hospital in Urban India. Gerontol Geriatr Med. 2020; 6: 2333721420910639.

https://doi.org/10.1177/2333721420910639 PMid:32284954 PMCid:PMC7139167

[55]. Avers, Dale, Brown, Marybeth, Chui, Kevin K, Wong, Rita A., Lusardi, Michelle. Use of the Term "Elderly", Journal of Geriatric Physical Therapy: 2011; 34 (4):153154. https://doi.org/10.1519/JPT.0b013e31823ab7ec PMid:22113395

[56]. Paul N S, Asirvatham M. Geriatric health policy in India: The need for scaling-up implementation. J Family Med Prim Care. 2016;5:242-7. https://doi.org/10.4103/2249-4863.192333 PMid:27843821 PMCid:PMC5084541

[57]. Mane AB. Elderly Care in India: Way Forward. J Gerontol Geriatr Res. 2016; 5: 339. https://doi.org/10.4172/2167-7182.1000339

[58]. D Jamuna. Issues of Elder Care and Elder Abuse in the Indian Context. Journal of Aging \& Social Policy. 2003; 15(2-3):125-42.

https://doi.org/10.1300/J031v15n02_08

PMid:14696693

[59]. R.Vinodh Rajkumar. Gravitational Torque Deficiency Syndrome - A Prospective Clinical Terminology- Part 1, Int J Physiother Res. 2016;4(5):1668-78.

https://doi.org/10.16965/ijpr.2016.161

[60]. R.Vinodh Rajkumar. Breathing Rate/Rhythm Evaluation Ascertains Total Health (BREATH): The Pulmonary Panacea. Int J Physiother Res 2020; 8(5): 3609 - 3619. https://doi.org/10.16965/ijpr.2020.161
[61]. R. Vinodh Rajkumar. Prevalence of Outward Deviation of Feet in Human Gait: A Non-participant Observation. Int J Physiother Res 2020;8(1):3378-3387.

https://doi.org/10.16965/ijpr.2020.101

[62]. R.Vinodh Rajkumar. Endomorphy dominance among non-athlete population in all the ranges of Body Mass Index. International Journal of Physiotherapy and Research 2015;3 (3):1068-1074.

https://doi.org/10.16965/ijpr.2015.139

[63]. R.Vinodh Rajkumar . Quantifying the Single Leg Balance using multiple dynamic postures on stable surface. Int J Physiother Res 2020;8(3):3462-70. https://doi.org/10.16965/ijpr.2020.130

[64]. R.Vinodh Rajkumar. Indirect estimation of the step length of walking and running performances on the treadmill. Int J Physiother Res 2020;8(2):3407-3414. https://doi.org/10.16965/ijpr.2020.110

[65]. Goldstein DS. Stress-induced activation of the sympathetic nervous system. Baillieres Clin Endocrinol Metab. 1987;1(2):253-78. https://doi.org/10.1016/S0950-351X(87)80063-0

[66]. Robinder JS Dhillon, Sarfaraz Hasni. Pathogenesis and Management of Sarcopenia. Clin Geriatr Med. 2017 ; 33(1): 17-26.

https://doi.org/10.1016/j.cger.2016.08.002 PMid:27886695 PMCid:PMC5127276

[67]. Ziemmsen T and Siepmann T. The Investigation of the Cardiovascular and Sudomotor Autonomic Nervous System - A Review. Front.Neurol. 2019; 10:53. https://doi.org/10.3389/fneur.2019.00053 PMid:30809183 PMCid:PMC6380109

\footnotetext{
How to cite this article:

R. Vinodh Rajkumar. RESISTING MORBIDITY AND MORTALITY (RMM): AN EQUITABLE PUBLIC HEALTH. Int J Physiother Res 2020;8(6):3693-3705. DOI: 10.16965/ijpr.2020.177
} 